\title{
Childhood Antecedents of Adult Sense of Belonging
}

\author{
Bonnie M. Hagerty, Reg Arthur Williams, and Hiroaki Oe \\ University of Michigan
}

Sense of belonging has been proposed to be a basic human need, and deficits in sense of belonging have been linked to problems in social and psychological functioning. Yet, there is little evidence about what early life experiences contribute to sense of belonging. The purpose of this study was to examine potential childhood antecedents of adult sense of belonging. The sample consisted of 362 community college students ranging in age from 18 to 72 years, with a mean age of 26 years. Measures included the Sense of Belonging Instrument, the Parental Bonding Instrument, and the Childhood Adversity and Adolescent Deviance Instrument. Multiple regression analysis was used to correlate childhood antecedents with adult sense of belonging. The final reduced model included 12 variables, which accounted for $25 \%$ of the variance in sense of belonging. Significant positive antecedents with a relationship with sense of belonging were perceived caring by both mother and father while growing up, participation in high school athletic activity, and parental divorce. Significant negative variables with a relationship with sense of belonging included perceived overprotection of father, high school pregnancy, family financial problems while growing up, incest, and homosexuality. Knowledge of these factors should influence interventions with families regarding child-rearing and parenting practices, mediating the effects of crises during childhood such as divorce and teen pregnancy, and the interpersonal growth needs of teenagers. (c) 2002 Wiley Periodicals, Inc. J Clin Psychol 58: 793-801, 2002.

Keywords: belonging; childhood; adolescence; mental health

Throughout the ages, human beings have demonstrated a need for interpersonal bonds, interactions with others that provide security, sustenance, safety, affection, companionship, and well-being. Sense of belonging has been proposed to be a basic human need (Maslow, 1962), and deficits in belonging have been associated with problems in both

NIMH Grant 5T01MH19643-02 and the University of Michigan School of Nursing supported this study. Correspondence concerning this article should be addressed to: Bonnie M. Hagerty, Ph.D., University of Michigan, School of Nursing, 400 N. Ingalls, Room 4350, Ann Arbor, MI 48109; e-mail: bmkh@umich.edu. 
social and psychological functioning (Hagerty, Williams, Coyne, \& Early, 1996). Hagerty, Lynch-Sauer, Patusky, Bouwsema, and Collier (1992) described sense of belonging as a unique concept, different from other interpersonal phenomena such as attachment and social support, and noted it to be a vital component of mental health.

While research has begun to demonstrate linkages between sense of belonging and functioning, processes by which an individual develops a sense of belonging remain unclear. Various psychosocial frameworks such as those from attachment and object relations theory suggest that foundational elements of interpersonal functioning are formed in infancy and childhood. Certainly, those early relationships with others, particularly caregivers, are influential in how young persons perceive themselves and behave in relation to others. Specifically, there is little evidence about what experiences in early life contribute are associated with sense of belonging as an adult. Therefore, the purpose of this study was to examine potential childhood antecedents of adult sense of belonging. This correlational study was a secondary analysis of a larger study designed to measure and investigate the concept of sense of belonging (Hagerty \& Patusky, 1995).

\section{Background}

Hagerty and associates (1992) advanced the concept of sense of belonging as a unique element of interpersonal relatedness, specifically defined as "the experience of personal involvement in a system or environment so that persons feel themselves to be an integral part of that system or environment" (p. 173). Following an extensive concept analysis using literature searches, clinical case examples, and focus groups, these researchers delineated two critical attributes of sense of belonging: (a) valued involvement or the experience of being valued and needed, and (b) fit, the person's perception that his or her characteristics articulate with or complement the system or environment. In addition, potential antecedents to belonging were identified including energy for involvement, the potential and desire for meaningful involvement, and the potential for shared or complementary characteristics (p. 174). Hagerty and colleagues (1992) also proposed that the consequences of sense of belonging included psychological, social, spiritual, or physical involvement; attribution of meaningfulness; and the establishment of a foundation for emotional and behavioral responses. Subsequent research utilizing an instrument designed specifically to measure sense of belonging based on its definition and critical attributes has supported the initial premise that sense of belonging is important to psychological and social functioning (Hagerty et al., 1996).

To this point, the development of sense of belonging and the processes by which this phenomenon promotes successful functioning have yet to be examined. Unfortunately, there is minimal understanding of the development and mechanisms of many of the concepts that purport to capture elements of relatedness, such as social support. Coyne and Bolger (1990), for example, argued that while there has been extensive investigation of social support, there is a need for understanding concepts that are more specific and based on processes within relationships that promote or hinder successful adaptation. Hagerty and Patusky (1995) posited that sense of belonging is unique and is an important element that comprises social support processes.

This study was designed to further explicate sense of belonging by examining those childhood experiences that might be related to sense of belonging as an adult. Sense of belonging, although multidimensional with emotional, cognitive, social, and behavioral facets, would seem to be rooted in early attachment systems that influence a person's developing view of self-in-relation to others. Thus, early parental interactions and life 
experiences within the family might be related to the development of adult sense of belonging.

In addition, other life experiences such as those in school and during adolescence also might be important in influencing sense of belonging. Research on the role of stressful life events indicates that even small events can be disruptive to interpersonal relationships, mood states, and functioning (Pillow, Zautra, \& Sandler, 1996). Ultimately, these disruptions can influence self-esteem, peer relationships, and social functioning (Allen, Hauser, Bell, \& O'Conner, 1994). Thus, stressors such as financial problems, frequent moves, or school difficulties may disrupt a child's or adolescent's interpersonal functioning and lead to a variety of attempts to cope such as running away, drug or alcohol abuse, or pregnancy, all of which may contribute to or detract from an individual's sense of belonging. It is unclear if these early life experiences are associated with sense of belonging as an adult.

\section{Methods}

\section{Design}

A correlational study was conducted using data from a larger project designed to examine sense of belonging (Hagerty \& Patusky, 1995). A relational design is meant to identify variables that are correlated with the phenomenon of interest. It is not meant to be explanatory, that is, no cause and effect can be inferred (Pedhazur \& Schmelkin, 1991).

\section{Sample}

This nonprobability sample consisted of 362 students attending a Midwestern community college. A community college was selected for its diverse groups of students.

\section{Measures}

Sense of Belonging Instrument-Psychological. The Sense of Belonging InstrumentPsychological (SOBI-P; psychological experience of fit and valued involvement) consists of 18 items scored on a 4-point Likert-type scale from 1 (strongly agree) to 4 (strongly disagree). The SOBI-P items address valued involvement ("If I died tomorrow, very few people would come to my funeral") and fit ("I often wonder if there is anyplace on earth where I really fit in"). Cronbach's coefficients alpha have been reported to range from .91 to .93 for the SOBI-P (Hagerty et al., 1996). Test-retest reliability with community college students over an eight-week period was .84. Evidence of content validity has been reported (Hagerty \& Patusky, 1995). Construct validity was supported through factor analysis, contrasting groups, and correlations with other related measures of loneliness and social support (Hagerty \& Patusky, 1995).

Parental Bonding Instrument. The Parental Bonding Instrument (PBI) measures two components of parental bonding, care, and overprotection. Items such as "Helped me as much as I needed" comprise the caring subscale whereas items such as "Tried to control everything I did" constitute the overprotection subscale. The PBI consists of 25 items that describe the parental behavior or attitude on a scale of 1 (very like) to 4 (very unlike). Respondents are asked to complete this scale for each parent, resulting in four scores: maternal caring, maternal overprotection, paternal caring, and paternal overprotection. Split-half reliability was reported to be .88 for the caring scale and .74 for the overpro- 
tection scale (Parker, Tupling, \& Brown, 1979). Construct validity was supported with factor analysis (Kazarian, Baker, \& Helmes, 1987; Parker et al., 1979) and was subsequently demonstrated through hypothesis testing with other constructs such as depression (Parker, 1979), anxiety (Parker, 1979), and schizophrenic relapse (Parker, Johnston, \& Hayward, 1988). The PBI has been reported to be useful for hypotheses testing "about the contributions of parental attitudes and behaviors to any condition in which deficiencies in parental characteristics may be a factor" (Gamsa, 1987, p. 291).

Childhood Adversity and Adolescence Deviance. Respondents are asked to check any of 16 adversities that may have occurred in their family while growing up and 12 events that may have occurred while in high school. These include: financial problems, frequent moves, drinking or drug problems, heated arguments between parents, mental health problems, separation or divorce of parents, remarriage of parents, violence between parents, parents having affairs, homosexuality, incest, death of immediate family member, chronic physical illness in family, violence toward children by parents, children running away, trouble with the law, date often, do well in school, participate in athletics or other school activities, have serious problems with one or both parents, play hooky or skip school or get suspended, get in trouble with the law, use alcohol, use drugs, runaway from home, have a steady girlfriend or boyfriend, have sexual intercourse, and get pregnant or get someone pregnant. Cohen, Coyne, and Duvall (1996) modified these items from a questionnaire initially devised by Kupfer, Detre, and Jacqueline (1974). Scores can be calculated by summing the number of items endorsed or by using each item as a categorical variable, as was done in this study. All items were intentionally worded to assess the occurrence of specific circumstances rather than the respondent's subjective evaluation of them.

\section{Procedures}

After approval for protection of human subjects, students at the community college were invited to participate in the study through announcements made in the classrooms by instructors and the researchers and through flyers posted and distributed throughout the college. Questionnaires were distributed to interested students in the lobby of a primary campus building. Students completed the questionnaires in nearby quiet rooms to ensure privacy.

\section{Results}

The mean age of participants was 26.2 years, with most respondents in early adulthood. Age was not a significant covariate on any of the study variables. Approximately $60 \%$ of the respondents were female, and $68 \%$ of the students were single. In addition, $65 \%$ were Caucasian, 22\% were African American, and 12\% were of Asian, Hispanic, or Native American descent. In this sample, $60 \%$ reported no prior history of mental health problems or treatment.

Some responses for all 25 items of the mother or father PBI scales were missing because the participant grew up without either a father or a mother, or both; 32 of the subjects had no father whereas eight of the subjects had no mother; four subjects had neither parent. To address this in the analysis, two new dummy variables were created indicating the nonexistence of a mother or father based on their responses to questions that asked about the existence of parents while growing up. Thus, the estimation of the 
effect of the PBI score was unaffected by these structurally missing entries. Twelve observations were excluded from the analysis because two or more missing PBI scores were not explained by the nonexistence of a parent. Thus, 350 participants were used throughout the analysis.

The childhood adversity and adolescent deviance checklist was examined for frequency of responses to each item. Table 1 depicts the number and percentage of respondents who marked "yes," that the situation had occurred in their lives, for each variable.

Multiple linear regression analysis was used to determine antecedents of adult sense of belonging from a set of 32 potential variables (childhood adversity and adolescent deviance experiences and maternal and paternal caring and overprotection). Regression diagnostic tests and residual analysis revealed that there were no violations of the basic assumptions of linear modeling. From an initial linear regression model, a simplified model was computed by deleting nonsignificant predictor variables sequentially. The final, reduced model included 12 variables, accounting for $25 \%$ of the variance in sense of belonging $\left(R^{2}=0.253\right)$. The estimated residual standard error was 8.4 . The 12 variables that comprised the final model are listed in Table 2.

The significant childhood family history variables in the model were family divorce, financial problems, incest, and homosexuality. Divorce in the family while growing up had a positive relationship to sense of belonging in that respondents who had experienced parental divorce had a higher sense of belonging than those without parental divorce. The other three variables - family financial problems, incest, and homosexuality—negatively related to sense of belonging. Incest and homosexuality, however, had few endorsements, with less than $5 \%$ of all participants marking these items.

One of the high school experience variables, participation in athletic activity, was significant in the final model and had a positive relationship with sense of belonging. The remaining high school experience variables had little relationship to the current sense of belonging.

Table 1

Frequency and Percentage of Yes Responses for Childhood Adversity and Adolescent Deviance

\begin{tabular}{lcclrr}
\hline High School Variables & Yes $n$ & $\%$ & Family Events Variables & Yes $n$ & $\%$ \\
\hline Have intercourse & 204 & 58 & Family financial problems & 169 & 48 \\
Do well in school* & 202 & 58 & Parental arguments & 139 & 40 \\
Athletics/other activities* & 200 & 57 & Death close family member & 123 & 35 \\
Steady boy/girlfriend* & 181 & 52 & Separation/divorce & 105 & 30 \\
Use alcohol & 176 & 58 & Drugs/alcohol in family & 103 & 29 \\
Hooky/suspension & 170 & 50 & Frequent moves & 66 & 19 \\
Date often* & 145 & 49 & Child ran away & 65 & 19 \\
Use drugs & 108 & 31 & Family legal trouble & 64 & 18 \\
Serious parent problems & 83 & 24 & Violence between parents & 53 & 15 \\
Run away from home & 49 & 14 & Violence to children & 52 & 15 \\
Get (someone) pregnant & 46 & 13 & Parent remarriage & 51 & 15 \\
Personal legal trouble & 38 & 11 & Parent affairs & 51 & 15 \\
& & & Mental health problems & 45 & 13 \\
& & & Chronic physical illness & 40 & 11 \\
& & & Incest in family & 13 & 4 \\
& & & Homosexuality & 11 & 3
\end{tabular}

Note. In high school variables, * indicates positive history. 
Table 2

Regression Parameter Estimates of the Childhood Predictors in Sense of Belonging

\begin{tabular}{lrcc}
\hline Variables & \multicolumn{1}{l}{ Beta } & SE & \multicolumn{1}{l}{$t$} \\
\hline Finances & -1.06 & 0.47 & $-2.20^{*}$ \\
Divorce & 1.12 & 0.51 & $2.18^{*}$ \\
Incest & -2.51 & 1.24 & $-2.02^{*}$ \\
Homosexuality & -2.82 & 1.33 & $-2.12^{*}$ \\
Athletics & 1.06 & 0.47 & $2.28^{*}$ \\
Pregnancy & -1.01 & 0.68 & -1.49 \\
No father & 0.54 & 0.82 & 0.65 \\
No mother & -0.36 & 1.54 & -0.23 \\
Father care & 0.23 & 0.06 & $3.90^{* * *}$ \\
Father overprotection & -0.25 & 0.08 & $-3.17^{* *}$ \\
Mother care & 0.21 & 0.06 & $3.68^{* * *}$ \\
\hline
\end{tabular}

$* p<.05 . * * p .01 . * * * p<.001$.

Among the four parental bonding variables, three were significantly correlated with sense of belonging: father caring, mother caring, and father overprotection. Mother overprotection did not enter into the model. Respondents who reported a higher sense of belonging also reported more caring by both parents. Father overprotection, however, was inversely related to sense of belonging, with more overprotection related to a lower sense of belonging.

\section{Discussion}

Links between childhood experiences and subsequent psychosocial functioning have been suggested and documented since Freud's hypotheses regarding early childhood influences on the development of adult neuroses (Maughan \& McCarthy, 1997). Using a retrospective design, results of this study suggest that certain experiences during childhood and adolescence are associated with sense of belonging as an adult. Several key variables emerged as possible antecedents to sense of belonging, including those from within the childhood family, high school experiences, and the perception of parental caring and overprotection.

Incest and homosexuality within the family of origin were significantly related to a lower sense of belonging as an adult, yet less than 5\% of the respondents endorsed these items. Thus, these results should be interpreted with caution. They are, however, congruent with research that supports a relationship between childhood sexual abuse, including incest, and negative adult consequences such as low self-esteem, depression, and difficulty in interpersonal relationships (Daie, Witztum, \& Eleff, 1989; Roesler \& McKenzie, 1994). Attention has been given to the alienation of young people who are gay or lesbian (D’Augelli \& Hershberger, 1993; Savin-Williams, 1994).

In the linear regression analysis, divorce within the family of origin was unexpectedly related to a higher sense of belonging. Although this seems to be in contrast to studies depicting the negative short- and long-term ramifications of divorce on children, there is recent acknowledgment that there are positive elements of divorce for the children. Stewart, Copeland, Chester, Malley, and Barenbaum (1997) found that after divorce, over time, children's adjustment improved with little psychological or behavioral disrup- 
tion. Viewing divorce as a systems event, Stewart and colleagues also considered the possibility that divorce, in disrupting family connections, forces the children to renegotiate relationships and find new ways to be part of newly formed family systems. In addition, Maughan and McCarthy (1997) noted that the effects of divorce are indirect and mediated by other adolescent experiences. Certainly, this finding requires additional investigation, raising more questions about the role of divorce in families.

Financial problems were negatively associated with sense of belonging. This is understandable given that financial concerns usually create stress and tension within families, potentially fostering disruption and lack of security. Financial problems may prevent children from having desired and socially acceptable material goods or from participating in various activities that promote social integration. The result may well be perceptions of being different, not fitting in, and not feeling valued and important vis-à-vis other children and adolescents.

An important antecedent of higher sense of belonging was participation in high school athletics. This may be due to the facilitation of social integration. According to Watson and Gibson (1980), this is accomplished through cooperation, mutually supportive behaviors, and relationships built on goal orientation. Participation also promotes a sense of competence, achievement, and mutual acceptance, all of which are important elements of being a valued part of a group.

Perceived childhood relationships with parents, as measured by the PBI, proved to be important and strongly correlated with adult sense of belonging. In fact, parent-child relationships had stronger relationships with adult sense of belonging than specific adverse events and high school experiences. Although childhood and high school experiences are considered to be potent influences on the psychosocial development of teenagers, our findings support the important role of parenting. There is evidence that close, supportive, and warm relationships between parent and child are important for future adult functioning (Mackinnon, Henderson, \& Andrews, 1991, 1993; Parker, 1983). Multiple psychological theories, including attachment and object relations theory, are founded on the basic premise that positive caring, nurturance, availability, and support contribute to an individual's eventual adjustment, sense of self and others, and ability to engage in mutually satisfying, caring relationships with others. People's perceptions that they are cared about as children appear to be an extremely important foundation for later interpersonal interactions and the ability to view ones' self as valued, important, and able to "fit in." Overprotection, however, particularly by the father, may interfere with the ability to develop and test out interpersonal relationships. In support of this, Mackinnon, Henderson, Scott, and Duncan-Jones (1989) found that higher levels of well-being were associated with more caring and less overprotection. Overall, the linkages between adult sense of belonging and perceptions of parental caring and overprotection suggest that a child's development and eventual functioning might be affected by parental style.

In conclusion, results of this study support the importance of parenting and certain childhood and adolescent experiences as associated with adult sense of belonging. These experiences were reported retrospectively, and thus may have been influenced by biased recall. Yet, the childhood adversity and deviance items were specifically designed to recall events rather than perceptions. Other limitations of the study included the small number of respondents who endorsed some childhood adverse experiences and volunteers whose participation may have reflected some biases.

While it is premature to infer explanation or cause-and-effect relationships, these initial results support the possibility that these childhood and adolescent experiences may contribute to or diminish adult sense of belonging. There is a continued need to document empirically evidence that links childhood factors to adult relatedness. Klohnen and Bera 
(1998), for example, demonstrated that early attachment orientations have continuity over the course of development, but underscore the need for more data regarding the consistency of these relationships over time. Certainly, additional study is required to determine how the effects of these variables may be enhanced or hindered by numerous mediating or moderating factors such as temperament of the individual or the availability of other supportive adults during childhood. While it may be more difficult to "undo" the negative effects of early experiences at a later point in life, these results speak to the importance of early intervention for families experiencing stressors, including those often ignored such as financial problems or homosexuality.

There is evidence that a strong sense of belonging is associated with better psychological and social functioning (Hagerty et al., 1996). A better understanding of the factors that influence sense of belonging, including identification of possible mediating factors, should inform interventions with families regarding parenting practices and style, and situational and crisis management of family difficulties. This may be one avenue for primary prevention of adult mental health difficulties.

\section{References}

Allen, J.P., Hauser, S.T., Bell, K.L., \& O'Connor, T.G. (1994). Longitudinal assessment of autonomy and relatedness in adolescent-family interactions as predictors of adolescent ego development and self-esteem. Child Development, 65, 179-194.

Cohen, N.J., Coyne, J.C., \& Duvall, J.D. (1996). Parents' sense of "entitlement" in adoptive and nonadoptive families. Family Process, 35, 441-456.

Coyne, J.C., \& Bolger, N. (1990). Doing without social support as an explanatory concept. Journal of Social and Clinical Psychology, 9, 148-158.

Daie, N., Witztum, E., \& Eleff, M. (1989). Long-term effects of sibling incest. Journal of Clinical Psychiatry, 50, 428-431.

D'Augelli, A.R., \& Hershberger, S.L. (1993). Lesbian, gay, and bisexual youth in community settings: Personal challenges and mental health problems. American Journal of Community Psychology, 21, 421-448.

Gamsa, A. (1987). A note on a modification of the Parental Bonding Instrument. British Journal of Medical Psychology, 60, 291-294.

Hagerty, B.M.K., Lynch-Sauer, J., Patusky, K., Bouwsema, M., \& Collier, P. (1992). Sense of belonging: A vital mental health concept. Archives of Psychiatric Nursing, 6, 172-177.

Hagerty, B.M.K., \& Patusky, K.L. (1995). Developing a measure of sense of belonging. Nursing Research, 44, 9-13.

Hagerty, B.M.K., Williams, R.A., Coyne, J.C., \& Early, M.R. (1996). Sense of belonging and indicators of social and psychological functioning. Archives of Psychiatric Nursing, 10, 235-244.

Kazarian, S.S., Baker, B., \& Helmes, E. (1987). The Parental Bonding Instrument: Factorial structure. British Journal of Clinical Psychology, 26, 231-232.

Klohnen, E.C., \& Bera, S. (1998). Behavioral and experiential patterns of avoidantly and securely attached women across adulthood: A 31-year longitudinal perspective. Journal of Personality and Social Psychology, 74, 211-223.

Kupfer, D.J., Detre, T., \& Jacqueline, K. (1974). "Deviant" behavior patterns in school children, application of KDS-TM-14. Psychological Reports, 35, 183-191.

Mackinnon, A.J., Henderson, A.S., \& Andrews, G. (1991). The Parental Bonding Instrument: A measure of perceived or actual parental behavior? Acta Psychiatrica Scandinavica, 83, 153-159.

Mackinnon, A.J., Henderson, A.S., \& Andrews, G. (1993). Parental "affectionless control" as an antecedent to adult depression: A risk factor refined. Psychological Medicine, 23, 135-141. 
Mackinnon, A.J., Henderson, A., Scott, R., \& Duncan-Jones, P. (1989). The Parental Bonding Instrument (PBI): An epidemiological study in a general population sample. Psychological Medicine, 19, 1023-1034.

Maslow, A.H. (1962). Toward a psychology of being. New York: Van Nostrand.

Maughan, B., \& McCarthy, G. (1997). Childhood adversities and psychosocial disorders. British Medical Bulletin, 53, 156-169.

Parker, G. (1979). Reported parental characteristics in relation to trait depression and anxiety levels in a nonclinical group. Australian and New Zealand Journal of Psychiatry, 13, 260-264.

Parker, G. (1983). Parental "affectionless control" as an antecedent to adult depression: A risk factor delineated. Archives of General Psychiatry, 40, 956-960.

Parker, G., Johnston, P., \& Hayward, L. (1988). Prediction of schizophrenic relapse using the Parental Bonding Instrument. Australian and New Zealand Journal of Psychiatry, 22, 283-292.

Parker, G., Tupling, H., \& Brown, L.B. (1979). A Parental Bonding Instrument. British Journal of Medical Psychology, 52, 1-10.

Pedhazur, E.J., \& Schmelkin, L.P. (1991). Measurement, design, and analysis: An integrated approach. Hillsdale, NJ: Erlbaum.

Pillow, D.R., Zautra, A.J., \& Sandler, I. (1996). Major life events and minor stressors: Identifying mediational links in the stress process. Journal of Personality and Social Psychology, 70, 381-394.

Roesler, T.A., \& McKenzie, N. (1994). Effects of childhood trauma on psychological functioning in adults sexually abused as children. Journal of Nervous Mental Disorders, 182, 145-150.

Savin-Williams, R.C. (1994). Verbal and physical abuse as stressors in the lives of lesbian, gay male, and bisexual youths: Associations with school problems, running away, substance abuse, prostitution, and suicide. Journal of Consulting \& Clinical Psychology, 62, 261-269.

Stewart, A.J., Copeland, A.P., Chester, N.L., Malley, J.E., \& Barenbaum, N.B. (1997). Separating together: How divorce transforms families. New York: Guilford Press.

Watson, G.G., \& Gibson, B.J. (1980). Determinants of social integration in children's sport teams: The case of Australian rules football. International Journal of Sport Psychology, 11, 75-90. 